\title{
Synthesis and Antioxidant Activity of Mixed Ligand Complex of Quercetin and Aspartic Acid with Cobalt(II)
}

Nasrullah Mahar ${ }^{1,2}$, Ahmed Ali Hulio ${ }^{2^{*}}$, Qadeer Khan Panhwar ${ }^{2}$, Hassan Imran Afridil ${ }^{1}$, Inamullah Mahar ${ }^{1}$ and Sarfarza A Mallah ${ }^{2}$

${ }^{1}$ National Centre of Excellence in Analytical Chemistry, University of Sindh, Jamshoro-76080, Pakistan

${ }^{2}$ Institute of Chemistry, University of Sindh, 76080 Jamshoro, Pakistan

\begin{abstract}
Mixed ligand complexes are widely used in the field of pharmaceutical science due to their curing nature to various diseases. The present study was aimed to synthesize and explore the antioxidant activity of cobaltquercetin-aspartic acid mixed ligand complex using quercetin $(\mathrm{Q})$ and aspartic acid $(\mathrm{AA})$ as ligands. The complex was synthesized by applying a versatile approach and characterized with the help of available sophisticated analytical techniques, example: FT-IR, UV-VIS, ${ }^{1} \mathrm{H}$ NMR, DSC and elemental analysis. The antioxidant activity of the free ligands as well as mixed ligand complex was also explored well and observed that mixed ligand complex is more antioxidant than the free ligands.
\end{abstract}

Keywords: Quercetin; Aspartic acid; Cobalt; Mixed ligand complex; Antioxidant

\section{Introduction}

Most of the biomolecules (vitamins, enzymes, amino acids, lipids etc.) present in our body are in the form of mixed ligand complexes coordinated with biologically important metals such as $\mathrm{Fe}, \mathrm{Cu}, \mathrm{Zn}$, $\mathrm{Co}$ and $\mathrm{Mg}$ etc. [1]. It has been reported that the synthetic mixed ligand complexes are biologically active against various pathogenic microorganisms and have increased their applications and activity in vivo processes [2-4]. Among these synthetic complexes, the hetero ligand complexes of flavonoids (quercetin) and amino acids (aspartic acid) with various biologically important metal ions $(\mathrm{Cu}, \mathrm{Zn}, \mathrm{Co}, \mathrm{Fe})$ can have promoting effects in body regulatory processes [5] (Figure 1).

Cobalt, as abiologicallyimportant metal, is an essential micronutrient for living organisms. It is involved in various biological processes in body [6]. It is essential to all animals, including humans, however excessive exposure can lead to tissue and cellular toxicity [7]. Cobalt has been shown to provide promising potential in clinical applications [8]. The ligands such as flavonoids (quercetin, rutin and morin) and amino acids (tryptophan, arginine, aspartic acid and alanine) have effective role in the field of biochemistry and pharmaceutics [9]. Quercetin is polyphenolic natural compound found in plant based foods $[10,11]$. It is one of the effective chelator with three possible chelating sites. It is used in various biological and pharmacological processes that is antioxidant, anti-allergic, anti-cardiovascular diseases, anti-ulcer, antiinflammatory and anti-viral potentials $[12,13]$.

The aspartic acid, another constituent of complexes have also significant role in enzyme-metal ion processes in vivo [14]. These are useful as antibacterial agents and work against Staphylococcus aureus, Escherichia coli and nutritive agents in humans and animals $[15,16]$. Aspartic acid provides energy to cells; which burn it to generate adenosine triphosphate that is a cellular energy currency [17]. It is useful but not indispensable in the human diet, it has significant role in gluconeogenesis, which is the process of making glucose, or sugar, when your dietary supply is low [18] (Figure 2).

Literature reveals that the mix ligand complexes of transition metals with flavonoids and amino acids have not been synthesized so far. Keeping in view these facts and immaculate uses of amino acids and flavonoids, present work emphasis the synthesis of mixed ligand complex of biologically important metal Co(II) with Q and AA.<smiles>O=c1c(O)c(-c2ccc(O)c(O)c2)oc2cc(O)cc(O)c12</smiles>

Figure 1: Quercetin.

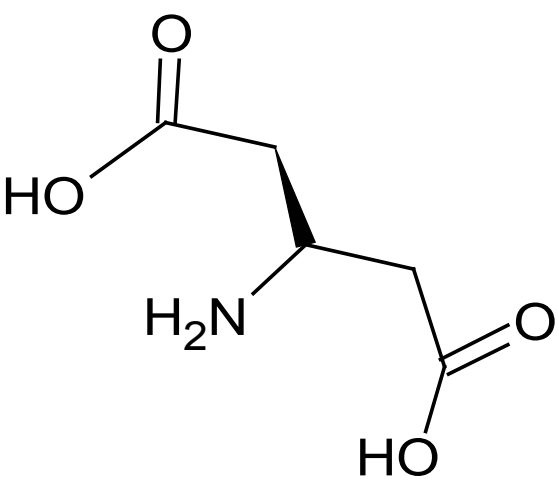

Figure 2: Aspartic acid.

*Corresponding author: Ahmed Ali Hulio, Institute of Chemistry, University of Sindh 76080 Jamshoro, Pakistan, Tel: +92222771681; E-mail: ahmedalihullio@yahoo.com

Received September 04, 2018; Accepted September 17, 2018; Published September 20, 2018

Citation: Mahar N, Memon S, Hulio AA, Panhwar QK, Mahar I, et al. (2018) Synthesis and Antioxidant Activity of Mixed Ligand Complex of Quercetin and Aspartic Acid with Cobalt(II). Med Chem (Los Angeles) 8: 253-258. doi: 10.4172/2161-0444.1000521

Copyright: @ 2018 Mahar N, et al. This is an open-access article distributed under the terms of the Creative Commons Attribution License, which permits unrestricted use, distribution, and reproduction in any medium, provided the original author and source are credited. 


\section{Experimental}

\section{Materials and methods}

All the reagents and solvents were of analytical or chemically pure grade. Quercetin dihydrate (2-(3,4-dihydroxyphenyl)-3,5,7-trihydroxy$4 \mathrm{H}$-1-benzopyran-4-one) was purchased from Sigma Aldrich and $\mathrm{CoCl}_{2} \cdot 6 \mathrm{H}_{2} \mathrm{O}$ from Fluka. HPLC grade methanol was obtained from Fisher scientific UK Ltd. $\mathrm{KBr}$ and DPPH were purchased from Aldrich Chemical Co. All reagents were weighed with an accuracy of $\pm 0.0001 \mathrm{~g}$.

UV-VIS spectra were obtained on Perkins Elmer Lambda 35 UVvisible double beam spectrophotometer using standard $1.00 \mathrm{~cm}$ quartz cells in methanol solvent. ${ }^{1} \mathrm{H}-\mathrm{NMR}$ spectra (in DMSO solvent) were obtained on a Bruker $500 \mathrm{MHz}$ spectrometer using TMS as internal reference. The IR spectra were recorded by using $\mathrm{KBr}$ pellets in the spectral range $400-4000 \mathrm{~cm}^{-1}$ on a Nicolet 5700 FT-IR instrument. The DSC curve was obtained using DSC $822^{e}$ Mettler Toledo (Heating rates

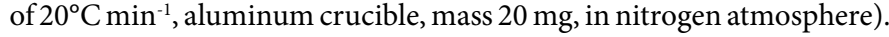
The elemental analyses for Carbon, Hydrogen and Nitrogen were obtained on microanalyses Perkins-Elmer 240c.

Synthesis of cobalt (II) complex: $20 \mathrm{~mL}$ equimolar quantities of metal chloride, Q and AA $(0.1 \mathrm{M})$ solutions were mixed in flask by equimolar ratios, that is $1: 1: 1$ at cold temperature $\left(-4^{\circ} \mathrm{C}\right)$. The $\mathrm{pH}$ of the contents was maintained at 6-8 in final mixture by using buffer. The mixture was kept on stirring for overnight at cold; the yellow green colored precipitates were obtained. The contents of the flask were evaporated in china dish to isolate the precipitates. The resulted product was washed and dried at room temperature. The precipitates weighed and the yield was calculated as $67 \%$ while melting point was measured by Gallenkamp apparatus. Elemental analysis found C, 46.25; H, 2.95; $\mathrm{N}, 2.50 \%$. Anal. Calc. for $\left[\mathrm{CoQ}(\mathrm{AA})\left(\mathrm{H}_{2} \mathrm{O}\right)_{2}\right] \mathrm{Cl}: \mathrm{C}, 46.46 ; \mathrm{H}, 2.87 ; \mathrm{N}$, $2.85 \%$.

\section{Results and Discussion}

\section{UV/VIS study}

It has been determined from elemental analyses data that the $\mathrm{Co}(\mathrm{II})$ mixed ligand complex of $\mathrm{Q}$ and $\mathrm{AA}$ is in 1:1:1 stoichiometry. The synthesis of such complex is denoted by the general formula $\mathrm{L}_{1} \mathrm{ML}_{1}^{\prime}$ given in equation (I):

$$
\mathrm{M}+\mathrm{L}_{1}+\mathrm{L}_{1}^{\prime} \rightarrow \mathrm{L}_{1} \mathrm{ML}_{1}^{\prime}
$$

For complexation, $\mathrm{Q}$ deprotonates at 3-OH functional group due to being more acidic and forms anionic specie then coordinates to metal ion to form metal complex. The $\mathrm{OH}$ group at position 5 is less acidic and is sterically hindered by first coordination at position 3. Similarly, the AA also forms anionic species by deprotonation at -COO functional group and complexation at $-\mathrm{NH}_{2}$ group also. The complex formation was further supported by the insolubility of the complex in water, methanol and dilute alkali solution. The Q, AA and their complex, in general, were non-hygroscopic and stable solids. The $\mathrm{Q}$ was easily soluble in Acetonitrile, DMF, DMSO and methanol, whereas the AA is soluble in $\mathrm{H}_{2} \mathrm{O}$, DMF, DMSO, Acetonitrile and the complex was having limited solubility in organic solvents. The complex was yellow green in color and thermally stable (Table 1), representing a strong metal-ligand bond. The elemental analyses data of the metal complex was consistent with their general formula as presented in equation (1).

The electronic spectrum for the complex is purely ligand-field spectrum. Where ligand such as quercetin shows the dominant peaks and undergoes bathochromic shift in its peaks after metal complex formation. The UV/Visible spectra for free Q, AA and complex is depicted in Figure 3, Q displays two major absorption bands band-I at $256 \mathrm{~nm}$ and band-II $375 \mathrm{~nm}$, band-I correspond to cinnamoyl system (ring B) while band-II corresponds to benzoyl system (ring-A), after complex formation band-II shows negligible bathochromic shift due to presence of amino acid while band-I was clearly seen to be shifted to longer wavelength with appearance of new band-III at $384 \mathrm{~nm}$. The band-I and new band-III show the bathochromic shift due to interaction of 3-OH and 4-CO oxygen with metal ion in Q. On other hand, - $\mathrm{COO}$ , $-\mathrm{NH}_{2}$ moieties of $\mathrm{AA}$ are also involved in complexation resulting in overall electronic redistribution between metal ion and both the ligand molecules to give extended pi bonding system. Due to more acidic nature of $3-\mathrm{OH}$, it is more probable chelating site in conjunction with oxo group in Q. In addition, - $\mathrm{COO}^{-}$and $-\mathrm{NH}_{2}$ sites of aspartic acid are more susceptible to be involved in complexation process. On the other hand, 5- $\mathrm{OH}$ group in $\mathrm{Q}$ is not involved in complexation process due to experiencing steric hindrance and having less acidic proton nature. Since, none of the single crystal has been isolated so far hence; crystallography is not possible here, however with the help of above data the tentative structure of metal complex has been given in Figure 4 .

\section{FT-IR study}

The coordination sites and the binding properties of $\mathrm{Q}$ and AA were determined by using IR spectroscopy. The prominent bands with tentative assignments are listed in Table 2, some useful data can be

\begin{tabular}{|c|c|c|}
\hline Complex & $\begin{array}{c}\text { Color and } \\
\text { texture } \\
\text { Yellow-green } \\
\text { precipitates }\end{array}$ & Melting point \\
\hline$\left[\mathrm{CoQ}(\mathrm{AA})\left(\mathrm{H}_{2} \mathrm{O}\right)_{2}\right] \mathrm{Cl}$ & $158^{\circ} \mathrm{C}$ \\
\hline
\end{tabular}

Table 1: Physicochemical properties of complex.

\begin{tabular}{|c|c|c|}
\hline Quercetin & Complex & Peak Type \\
\hline 3251 & 3262 & $-\mathrm{OH}$ \\
\hline $1660 / 1601$ & $1667 / 1601$ & $\mathrm{C}=\mathrm{O}$ \\
\hline 1611 & 1605 & Ring A and B \\
\hline 1561 & 1557 & $\mathrm{C}=\mathrm{C}$ \\
\hline & 1510 & Ring C, $\mathrm{C}_{4}=\mathrm{O}_{2}$ \\
\hline & 1431 & Ring C, $\mathrm{C}_{3}=\mathrm{O}_{3}$ \\
\hline 1316 & 1361 & Ring B, $\mathrm{C}_{4}-\mathrm{OH}$ \\
& $\mathrm{C}_{3}-\mathrm{OH}$ \\
\hline 1257 & 1240 & $\mathrm{C}-\mathrm{O}-\mathrm{C}$ \\
\hline & 541 & $\mathrm{Co}-\mathrm{O}$ \\
\hline & 592 & $\delta \mathrm{OH}$ \\
\hline
\end{tabular}

Table 2: Relative FT-IR spectral assignments of quercetin and complex.

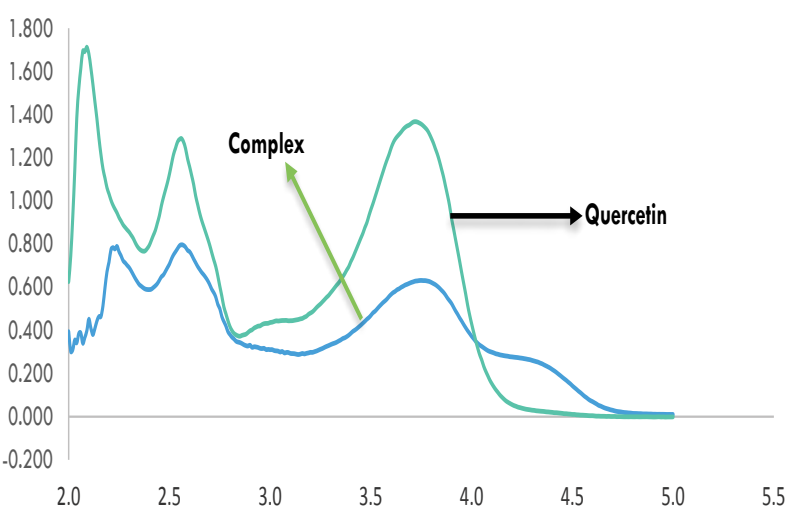

Figure 3: UV/Vis spectra of quercetin, aspartic acid and mix ligand complex of $\mathrm{Co}(\mathrm{II})$. 
attained by comparing the IR spectra of free $\mathrm{Q}$ and AA with resulting complex (Figure 5). The $\mathrm{C}=\mathrm{O}$ stretching mode of the free $\mathrm{Q}$ occurs at $1660 \mathrm{~cm}^{-1}$, which has been shifted to $1667 \mathrm{~cm}^{-1}$ after complex formation. This shift proposes the coordination of carbonyl oxygen with metal ion.

The decrease in $\mathrm{C}=\mathrm{O}$ bond order when coordinated to metal ion along with 3-OH, in complex may give rise to coupling of the vibrations of these two bands. The new bands at around 1610 and $1453 \mathrm{~cm}^{-1}$ are related with the anti-symmetric and symmetric stretching modes of the $\mathrm{C}-\mathrm{O}$ group at the chelating site, respectively. The bands positioned at 1611 and $1257 \mathrm{~cm}^{-1}$ pertained to $v(\mathrm{C}=\mathrm{C})$ and $v(\mathrm{C}-\mathrm{O}-\mathrm{C})$ frequencies are somewhat shifted by complex. The $v(\mathrm{C}-\mathrm{O}-\mathrm{H})$ deformation mode

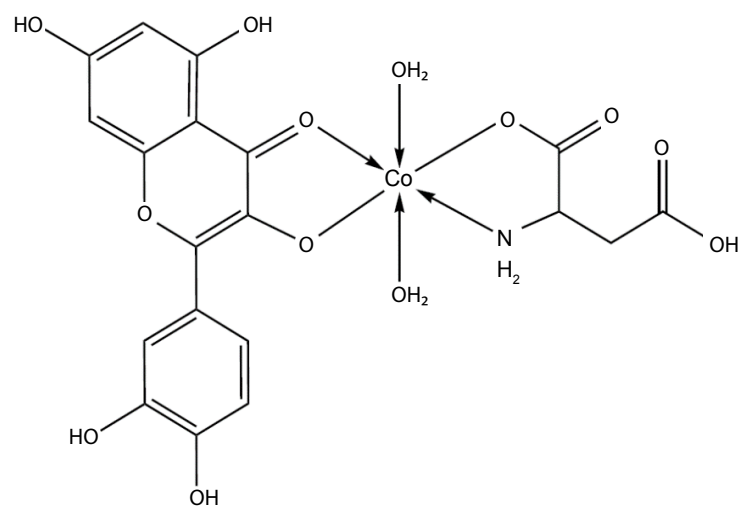

Figure 4: Chemical structure for mix ligand complex of $\mathrm{Co}(\mathrm{II})$.
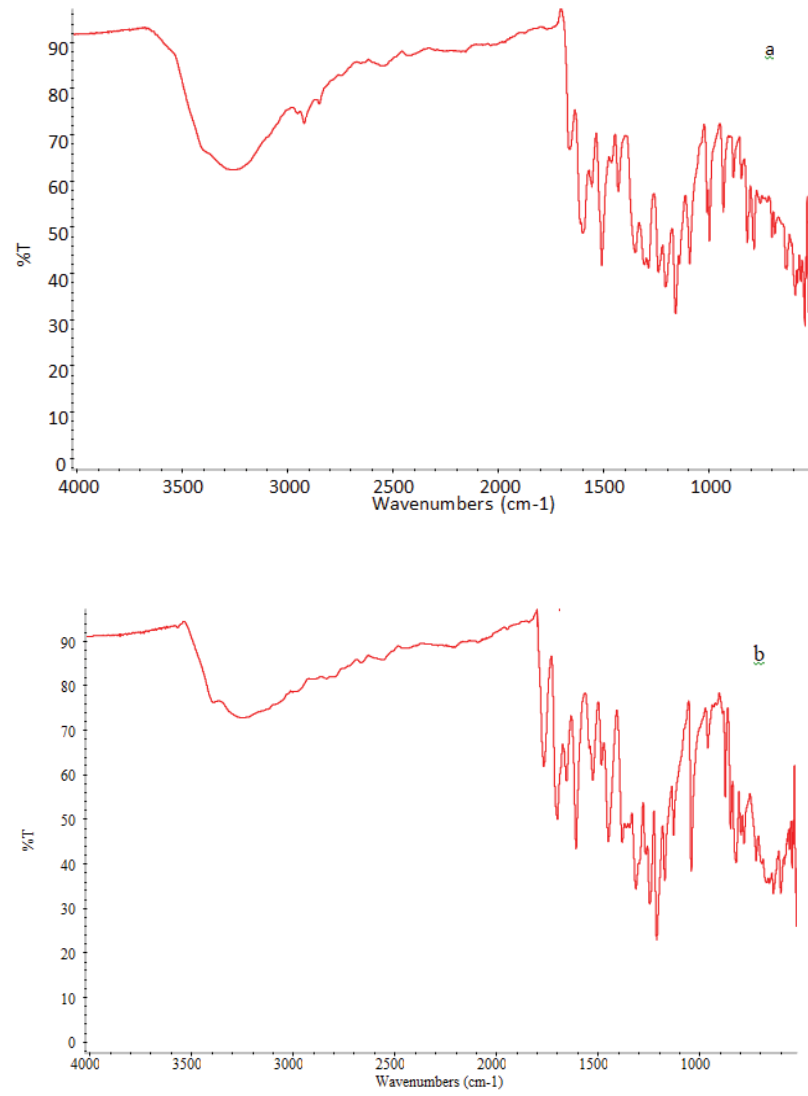

Figure 5: Comparative FT-IR spectra for a) complex, b) quercetin. observed at $1319 \mathrm{~cm}^{-1}$ in the ligand is shifted to $1361 \mathrm{~cm}^{-1}$ in the complex demonstrating an increase in bond order, which is usually observed when metal coordination involves with the ortho-phenolic $v(\mathrm{O}-\mathrm{H})$ group on the Q (ring B). Additionally, the occurrence of $v(\mathrm{M}-\mathrm{O})$ stretching vibration at $541 \mathrm{~cm}^{-1}$ indicates the formation of metal complex, while the ligand displays no such band.

The AA is coordinated from other side of the plane to same metal ion is indicated from spectral change caused by $\mathrm{N}-\mathrm{H}$ asymmetric and N-H symmetric vibrations observed at $\sim 2955$ and $\sim 2655 \mathrm{~cm}^{-1}$, respectively. These stretching vibrations have been shifted to higher value that is $3251 \mathrm{~cm}^{-1}$ in the spectrum of complex. It suggests the coordination of the two metal ions through nitrogen. The asymmetric $v\left(\mathrm{COO}^{-}\right)$band of the free AA that is $\sim 1581 \mathrm{~cm}^{-1}$ is shifted to higher wave number, that is $1601 \mathrm{~cm}^{-1}$. In addition, the symmetric $v(\mathrm{COO})$ mode observed at $\sim 1420 \mathrm{~cm}^{-1}$ is shifted to lower wave number, that is $1350 \mathrm{~cm}^{-1}$ in the of complex spectrum. It indicates that the coordination of the carboxylic acid group to metal ion has taken place via oxygen. Besides this, some new bands of weak intensity were observed at 592 and $563 \mathrm{~cm}^{-1}$ attributed to $\mathrm{M}-\mathrm{O}$ and $\mathrm{M}-\mathrm{N}$ vibrations, respectively. It is seen that these vibrational bands are absent in the spectrum of free aspartic acid. Some important bands of complex and free ligands are shown in Table 3.

\section{DSC study}

The DSC study shows characteristic thermal events at heating rate of $10^{\circ} \mathrm{C} \mathrm{min}^{-1}$. The DSC curve of complex shows some definite endothermic and exothermic changes and series of thermal events that show the dehydration, melting and series decomposition. It has been noted that thermal event observed at $45^{\circ} \mathrm{C}$ is due to dehydration consistent with mass loss. The endothermic peak at $158^{\circ} \mathrm{C}$ is representing the melting point of the complex as observed in thermogram (Figure 6). Whereas the series of small and very broad exothermic peaks indicate the sequential degradation of organic part of complex compound at the $161^{\circ} \mathrm{C}, 241^{\circ} \mathrm{C}$ and $250^{\circ} \mathrm{C}$ respectively. All the exothermic and endothermic peaks show agreement with relevant mass changes (Table 4).

\section{${ }^{1} \mathrm{H}-\mathrm{NMR}$ study of complex}

The ${ }^{1} \mathrm{H}-\mathrm{NMR}$ data (Table 5) show the downfield chemical shift in Co-Q-AA complex as compared to free ligands due to their coordination with metal ion. The quercetin (Figure 7a) coordinates with metal by replacing 3-OH proton, which is evident from ${ }^{1} \mathrm{H}-\mathrm{NMR}$ spectrum of complex (Figure $7 \mathrm{~b}$ ) where signal at $3-\mathrm{OH}$ is missing which suggests the quercetin coordination position with metal. The coordination of aspartic acid with metal ion is confirmed by shift in ${ }^{1} \mathrm{H}-\mathrm{NMR}$ signals in complex spectrum compared to free aspartic acid such as the N-H signal intensity is decreased due to coordination with metal, besides, all the ${ }^{1} \mathrm{H}$-NMR signals related to aspartic experience downfield shift due to conjugation and coordination with metal ion.

\section{Antioxidant activity of complex by DPPH radical scavenging method}

In our body, number of biochemical processes going on every time, which results in formation of various biomolecules. Among these useful moieties some highly reactive and potentially damaging chemical substances are also formed, such as hydroxyl radicals, hydrogen peroxide and superoxide anions [19]. These reactive oxygen species (ROS) can cause serious chronic diseases that is, cancer, aging and coronary heart disease etc., by altering the structure of lipids, fats, proteins and various other biomolecules[20]. For healthy life these ROS 


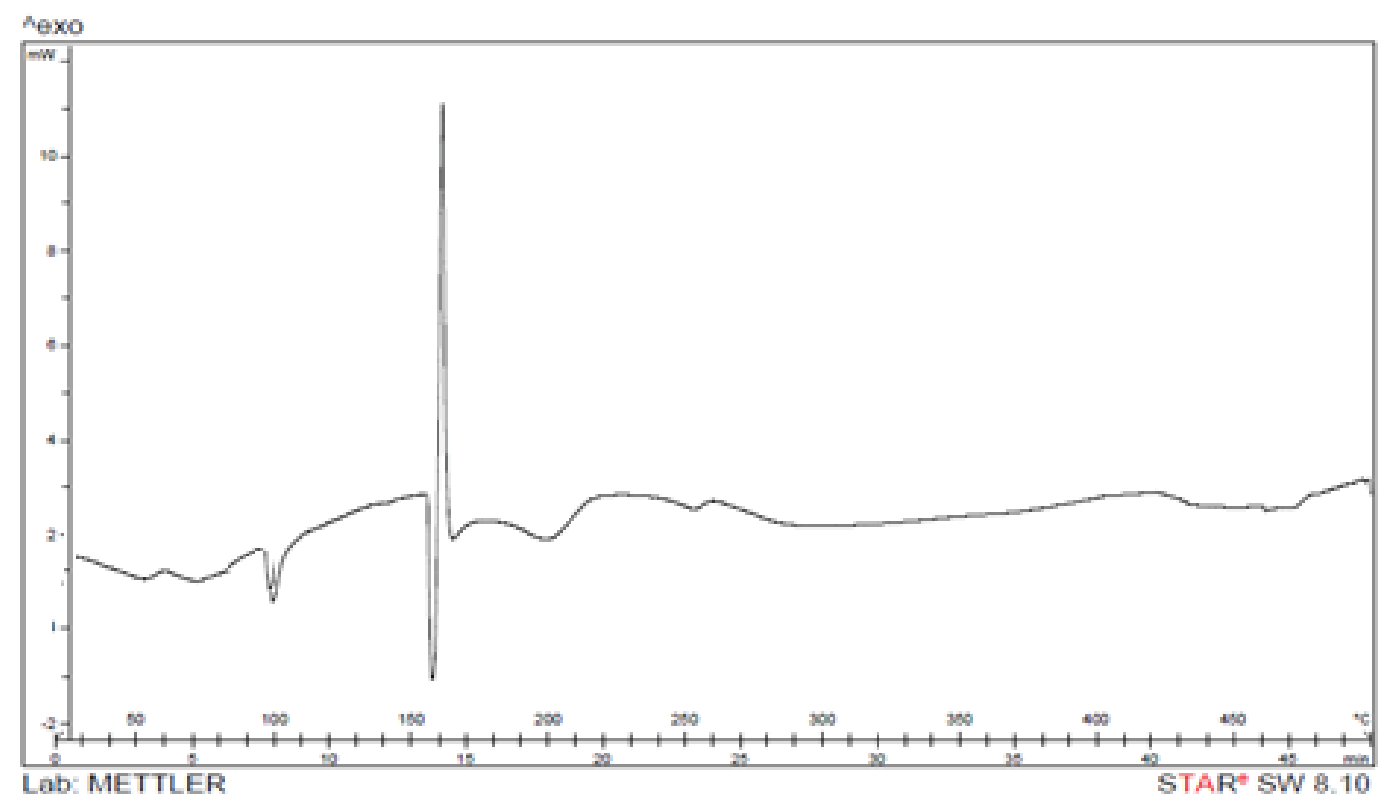

Figure 6: DSC study for mix ligand complex of $\left[\mathrm{CoQ}(\mathrm{AA})\left(\mathrm{H}_{2} \mathrm{O}\right)_{2}\right] \mathrm{Cl}$.

a.

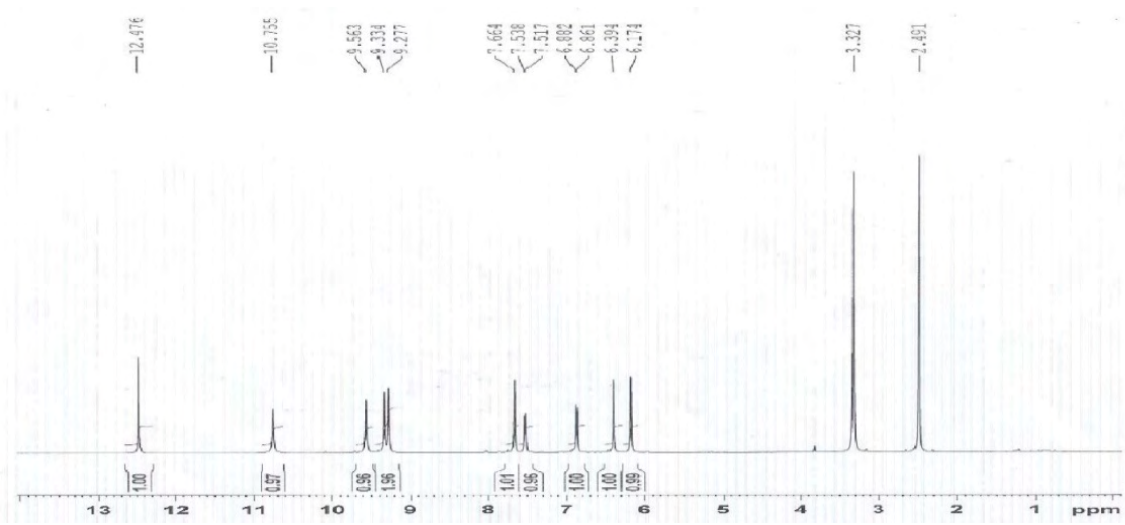

b.

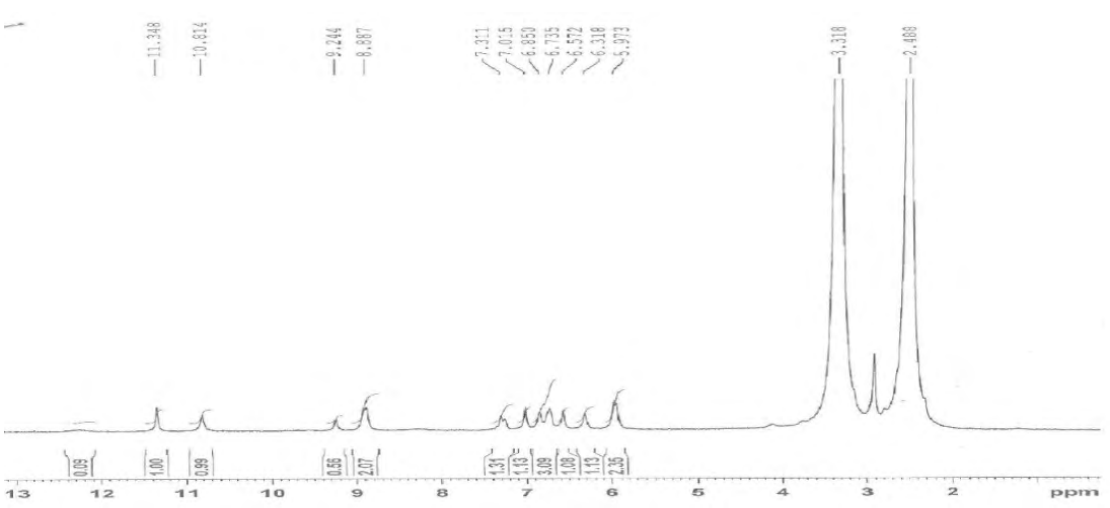

Figure 7: ${ }^{1} \mathrm{H}-\mathrm{NMR}$ spectra for a) quercetin and b) Co-Q-AA complex.

are trapped by some natural antioxidants in our body or artificially by incorporating synthetic drugs. There are vast numbers of metal complex based drugs synthesized in laboratory as antioxidants to prevent these free radicals. The antioxidant activity of Co-Q-AA and free ligands was measured for their scavenging ability through UV-VIS spectrophotometer with the help of DPPH free radical (Figure 8). The 


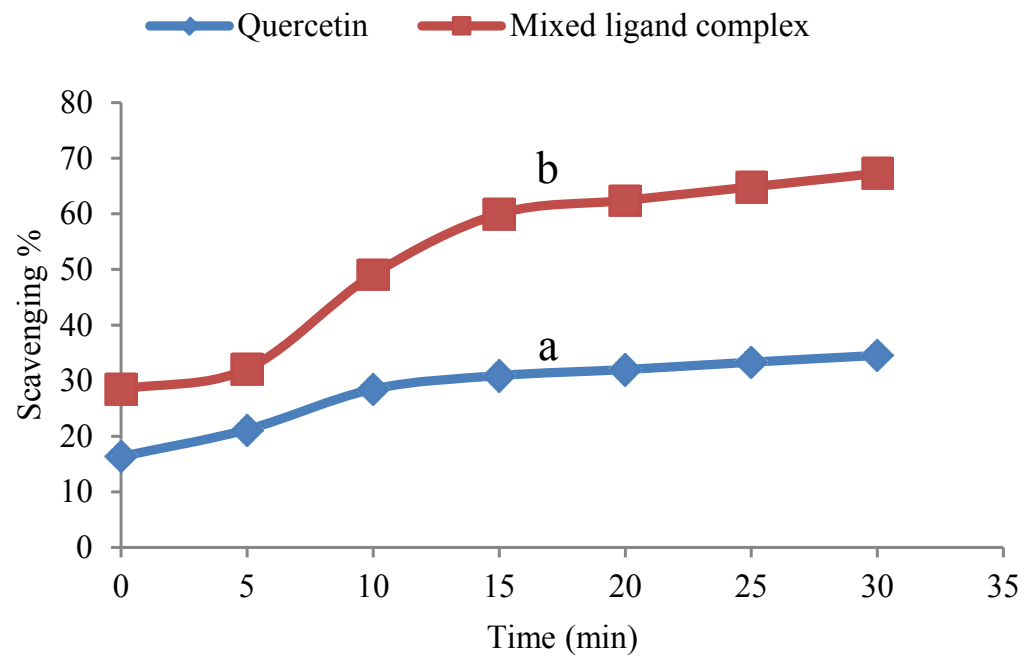

Figure 8: Antioxidant activity for a) quercetin and b) mixed ligand complex.

\begin{tabular}{|c|c|c|}
\hline Aspartic acid & Complex & Peak type \\
\hline $2955 / 2655$ & 3251 & N-H asymmetric and symmetric \\
\hline 1686 & 1667 & C=O \\
\hline $1581 / 1505$ & $1601 / 1510$ & COO- (asymmetric) \\
\hline 1420 & 1350 & COO- (symmetric) \\
\hline 989 & 930 & C-N \\
\hline $663 / 598$ & $592 / 563$ & M-N, M-O \\
\hline
\end{tabular}

Table 3: Relative FT-IR spectral assignments for aspartic acid and complex.

\begin{tabular}{|c|c|c|}
\hline $\begin{array}{c}\text { Complex and } \\
\text { Ligands }\end{array}$ & Temperature & Type of event \\
\hline \multirow{2}{*}{ Quercetin } & $124^{\circ} \mathrm{C}$ (Melting) & Endotherm \\
\cline { 2 - 3 } & $331^{\circ} \mathrm{C}$ (Decomposition) & Endotherm \\
\hline \multirow{2}{*}{ Aspartic Acid } & $227^{\circ} \mathrm{C} \mathrm{(Decomposition)}$ & Endotherm \\
\hline \multirow{2}{*}{ Complex } & $384^{\circ} \mathrm{C}$ & Exothermic \\
\hline & $158^{\circ} \mathrm{C} \mathrm{(Melting)}$ & Endotherm \\
\hline
\end{tabular}

Table 4: Thermal data for characteristic thermal changes in ligands as well as their complex.

\begin{tabular}{|c|c|c|}
\hline Type of H & Quercetin signals (in ppm) & $\begin{array}{c}\text { Complex } \\
\text { signals } \\
\text { (in ppm) }\end{array}$ \\
\hline $5-\mathrm{OH}$ & 12.74 & 11.34 \\
\hline $7-\mathrm{OH}$ & 10.75 & 10.81 \\
\hline $3-\mathrm{OH}$ & 9.56 & - \\
\hline $4 '-\mathrm{OH}$ & 9.33 & 9.24 \\
\hline $3 '-\mathrm{OH}$ & 9.27 & 8.88 \\
\hline $2 '-\mathrm{H}$ & 7.66 & 7.31 \\
\hline $6 '-\mathrm{H}$ & 7.53 & 7.01 \\
\hline $5 '-H$ & 6.88 & 6.73 \\
\hline $8-\mathrm{H}$ & 6.39 & 6.57 \\
\hline $6-\mathrm{H}$ & 6.17 & 6.31 \\
\hline
\end{tabular}

Table 5: ${ }^{1} \mathrm{H}-\mathrm{NMR}$ data for the various protons in quercetin and complex compound.

reaction between analyte and DPPH occurs in two steps: (I) DPPH absorbance $\left(\lambda_{\max }=515 \mathrm{~nm}\right.$ in methanol) decays quickly (typical time, 60-120 sec); and (II) DPPH absorbance decays slowly in $\sim 1 \mathrm{~h}$ to reach a constant value. In fact the molecular structure of flavonoids plays an important role in their antioxidant activity. Similarly, the increase in antioxidant activity of this species is due to appreciable involvement from 3-OH of $\mathrm{C}$ ring. Actually, $\mathrm{H}$-atom transfer may take place from 3-OH of Quercetin to DPPH during reaction assisting the abstraction process as well as stabilizing corresponding radical formed later on. The mixed ligand complex [CoQAA $\left(\mathrm{H}_{2} \mathrm{O}\right)_{2}$ ] exhibit higher antioxidant activity comparative to free ligand. Therefore, it indicated that chemical properties of considerable changed by the $\mathrm{Co}(\mathrm{II})$ metal ion. In reaction of quercetin to DPPH radical, a $\mathrm{H}$ atom is abstracted from the $\left[\mathrm{CoQAA}\left(\mathrm{H}_{2} \mathrm{O}\right)_{2}\right]$ to give a semiquinone complex which is stabilized by the metallic center and by conjugation with the $3-\mathrm{OH}$ group. This property is not only unique for the $\mathrm{Co}$ (II) ion but it is reported [21] that it is also showed by some other metals but some time less effective than the $\mathrm{Co}(\mathrm{II})$ ion, the oxidation potential is decreased on metal complexation with flavonoids, hence complexed quercetin becomes higher antioxidant compared to uncomplexed one.

\section{Conclusion}

It has been concluded from the study that synthesis of mixed ligand complex of Co with two ligands quercetin and aspartic acid has been confirmed from UV-VIS, IR, NMR as well as elemental analysis. The complex has the melting point $158^{\circ} \mathrm{C}$. The UV/VIS study shows the bathochromic shift as well as a new peak appeared from a d-d transition of $\mathrm{d}^{7}$ system in a Co metal ion. FT-IR study reveals the formation of new bonds between metal and ligands. In addition, NMR shows the replacement of specific protons to evidence the proper sites of coordination. While DSC indicates the melting point as well as oxidation degradation of compound. A tentative structure of the compound has also been given which is fully supported by results evidenced by various analytical techniques. The newly synthesized complex is observed to be more antioxidant than ligand molecules. It may be the best available agent against the carcinogens in future.

\section{Acknowledgements}

The authors are thankful to the National Center of Excellence in Analytical Chemistry for providing the facility of labs and instruments.

\section{References}

1. Finney LA, O'halloran TV (2003) Transition metal speciation in the cell: insights from the chemistry of metal ion receptors. Science 300: 931-936.

2. Yang P, Kong X, Cheng C, Li C, Yang X, et al. (2011) Synthesis and biological evaluation of 8 -substituted and deglucuronidated scutellarin and baicalin 
Citation: Mahar N, Memon S, Hulio AA, Panhwar QK, Mahar I, et al. (2018) Synthesis and Antioxidant Activity of Mixed Ligand Complex of Quercetin and Aspartic Acid with Cobalt(II). Med Chem (Los Angeles) 8: 253-258. doi: 10.4172/2161-0444.1000521

analogues as antioxidant responsive element activators. Science China Chemistry 54: 1565.

3. Patil SS, Thakur GA, Shaikh MM (2011) Synthesis, Characterization, and Antibacterial Studies of Mixed Ligand Dioxouranium Complexes with 8-Hydroxyquinoline and Some Amino Acids. ISRN Pharmaceutics.

4. El-Sherif AA, Shehata MR, Shoukry MM, Barakat MH (2012) Thermodynamic investigation and mixed ligand complex formation of 1, 4-Bis-(3-aminopropyl)piperazine and biorelevant ligands. Bioinorganic Chemistry and Applications.

5. Cheng IF, Breen K (2000) On the ability of four flavonoids, baicilein, luteolin, naringenin, and quercetin, to suppress the Fenton reaction of the iron-ATP complex. Biometals 13: 77-83.

6. Ahmed K, Yasmin F, Hussain N (2016) Green synthesis of nickel nanoparticles by using plant leaf extract as reducing agent. Science International 28: 2511.

7. Chang EL, Simmers C, Knight DA (2010) Cobalt complexes as antiviral and antibacterial agents. Pharmaceuticals 3: 1711-1728.

8. Xiao Y, Yuen J (2011) The biological application of cobalt. In: Cobalt: Characterizatics, Compounds and Applications. Nova Science Publishers, pp: 307-317.

9. Bonina F, Lanza M, Montenegro L, Puglisi C, Tomaino A, et al. (1996) Flavonoids as potential protective agents against photo-oxidative skin damage. International Journal of Pharmaceutics 145: 87-94.

10. Pratt DE, Hudson BJ (1990) Natural antioxidants not exploited commercially. In: Food antioxidants. Springer, pp: 171-191.

11. Panhwar QK, Memon S (2012) Synthesis and properties of zirconium (IV) and molybdate (II) morin complexes. Journal of Coordination Chemistry 65: 1130-1143.
12. Cornard JP, Merlin JC (2002) Complexes of aluminium (III) with isoquercitrin spectroscopic characterization and quantum chemical calculations. Polyhedron 21: $2801-2810$.

13. Dehghan G, Khoshkam Z (2012) Tin (II)-quercetin complex: synthesis, spectral characterisation and antioxidant activity. Food Chemistry, 131(2), 422-426.

14. Ritz TS, Collins MJ (2002) Racemization of aspartic acid in human proteins. Ageing research reviews 1: 43-59.

15. Iqbal MS, Khurshid SJ, Iqbal MZ (1990) Antibacterial activity of copper-amino acid complexes. J Pak Med Assoc 40: 221-222.

16. Voet D, Voet JG (1995) Biochemistry. Wiley, New York.

17. Laplace JP, Darcy-Vrillon B, Perez JM, Henry Y, Giger S, et al. (1989) Associative effects between two fibre sources on ileal and overall digestibilities of amino acids, energy and cell-wall components in growing pigs. British Journal of Nutrition 61: 75-87.

18. Sklan D, Noy $Y$ (2004) Catabolism and deposition of amino acids in growing chicks: effect of dietary supply. Poultry science $83: 952-961$.

19. Ejidike IP, Ajibade PA (2015) Synthesis, Characterization, Anticancer, and Antioxidant Studies of Ru(III) Complexes of Monobasic Tridentate Schiff Bases Reviews in Inorganic Chemistry 35: 191-224.

20. Akila E, Usharani M, Rajavel R (2013) Synthesis, Characterization and Biological Studies of Metal(II) Complexes of (3E)-3-[(2-\{(E)-[1-(2,4-Dihydroxyphenyl) ethylidene]amino\}ethyl)imino]-1-phenylbutan-1-one Schiff Base. Int J Pharm Pharmaceutical Sciences 5: 573.

21. Malešev D, Kuntić V (2007) Investigation of metal-flavonoid chelates and the determination of flavonoids via metal-flavonoid complexing reactions. Journal of the Serbian chemical society 72: 921-939. 